\title{
فعالية نظام الإحالة المباشرة على المحكمة وفقا للأمر 15-02
}

\section{Effectiveness of the court's referral système in accordance}

order 15-02

تاريخ الاستلام : 2020/01/18 ؛ تاريخ القبول : 2020/11/23

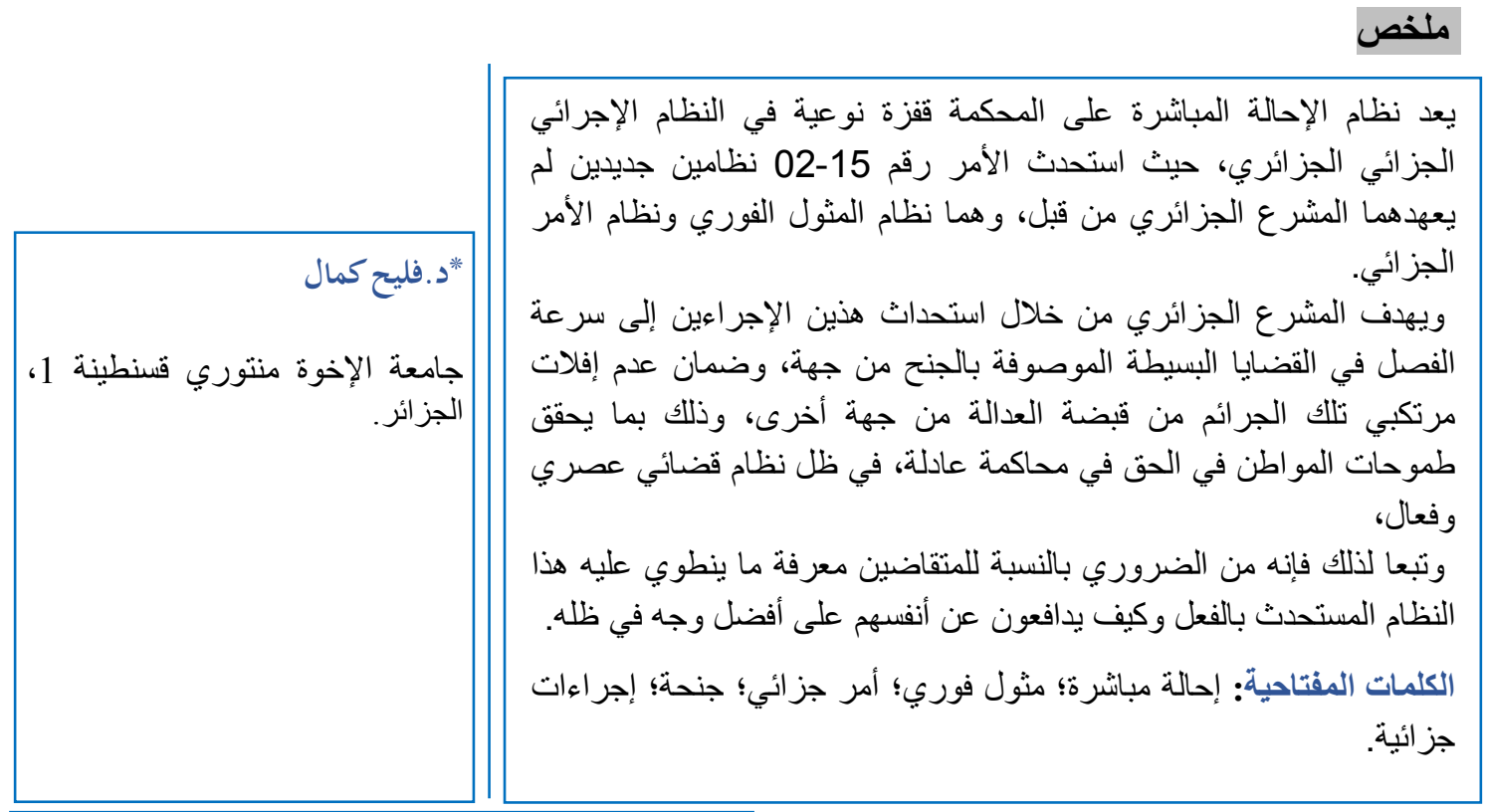

\section{Abstract}

The court's direct referral system is considered a qualitative leap in the Algerian penal procedure system, where order No. 15-02 created two new systems not previously pledged by the Algerian legislature. They are the brought promptly system and the penal order system.

Through the introduction of these two procedures, the Algerian legislature aims to expedite the adjudication of minor cases described as delicts on the one hand and to ensure that the perpetrators of these crimes do not escape justice on the other, in order to fulfill the citizen's aspirations for a fair trial, In a modern and effective judicial system, it is therefore essential for the judges to know what this system is already in place and how to best defend themselves.

Keywords: direct referral; brought promptly; penal order; misdemeanor. Criminal Procedure.

\section{Résumé}

Le renvoi direct à la Cour est un progrès qualitatif dans le système de procédure pénale algérien, où l'ordonnance $\mathrm{n}^{\circ}$ 15-02 a créé deux nouveaux systèmes qui n'avaient pas été établis auparavant par le législateur algérien, à savoir, le système de la comparution immédiate et l'ordre pénal.

Par l'introduction de ces deux procédures, le législateur algérien vise à atténuer la crise de la justice pénale. En tranchant rapidement les cas simples décrits comme délits d'une part, et en veillant à ce que les auteurs n'échappent pas à la justice de l'autre, garantir ainsi l'âge du secteur de la justice et réaliser les aspirations du citoyen à un procès équitable, dans un système judiciaire moderne et efficace,

Il est important pour le justiciable de savoir à quoi correspond concrètement cette procédure et comment se défendre au mieux.

Mots clés : renvoi direct; comparution immédiate ; ordre pénal ; délit ; procédure pénal.

* Corresponding author, e-mail: boure1983@live.com

$$
\text { (C) جامعة الاخوة منتوري قسنطينة 1، الجزائر } 2020 .
$$


لقد استحدث المشرع الجزائري بموجب الأمر رقم 15-02 (1) طريقا

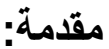

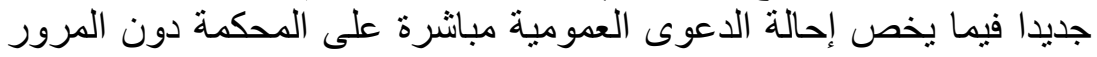

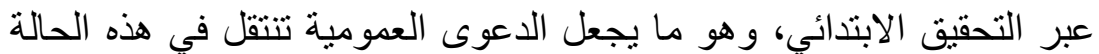

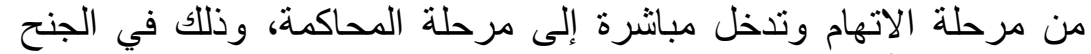

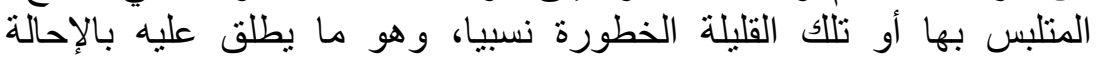

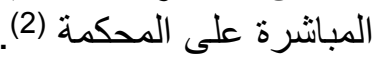

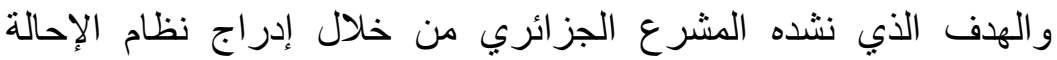

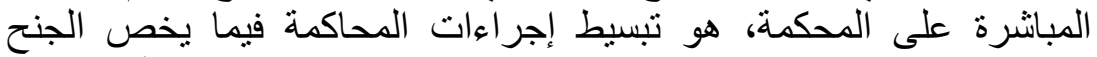

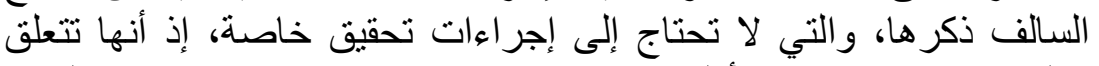

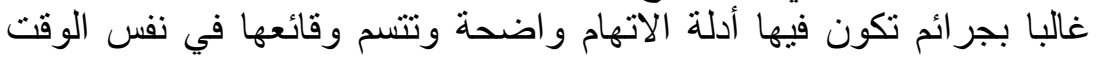

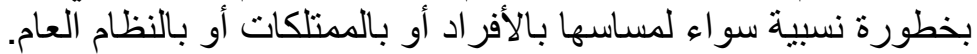

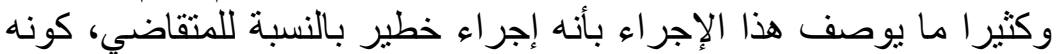

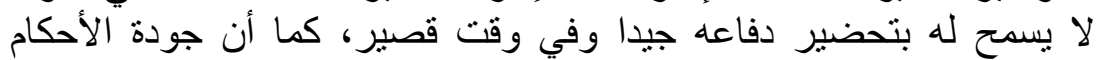

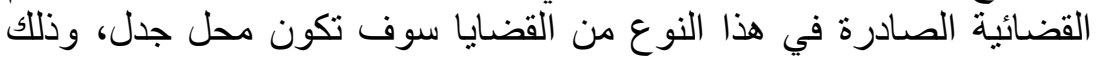

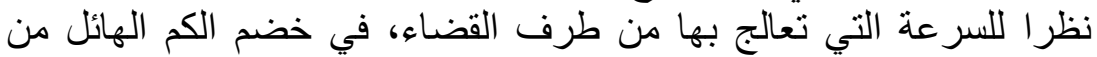

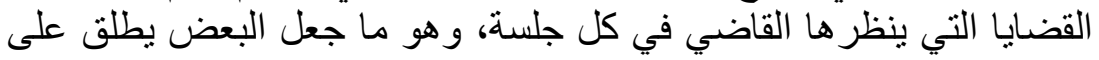

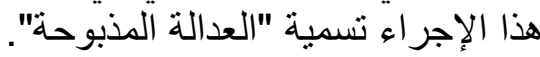

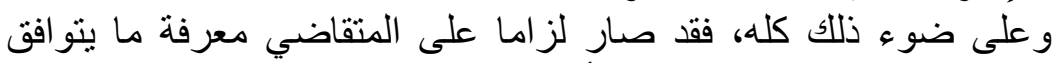

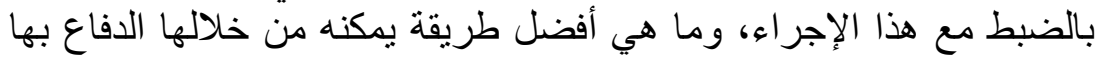
عن نفسه. و انطلاقا مما تقدم ذكره، سنحاول معالجة هذا الموضوع الإلة وفقا للإشكالية

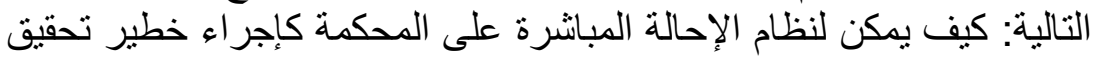

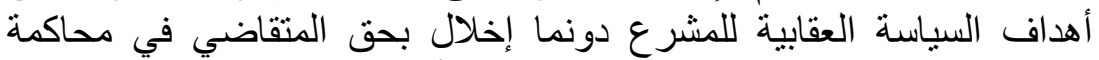

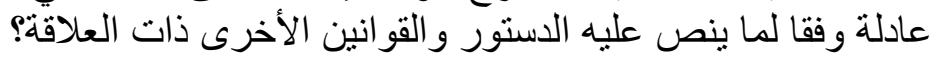

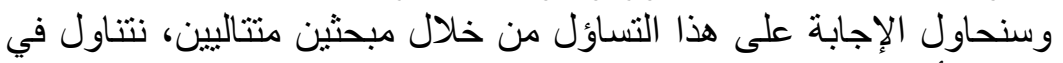
المبحث الأول نظام المثول الفوري، ثم نتطرق في الإن المبحث الثاني إلى نظام

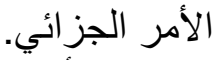
المبحث الأول: نظام المثول الفوري أمام المحكمة:

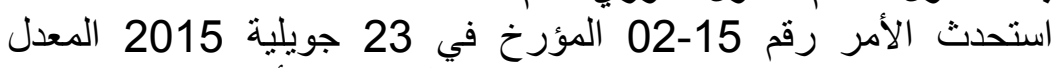

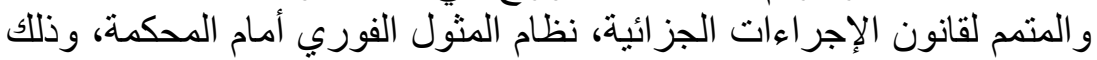

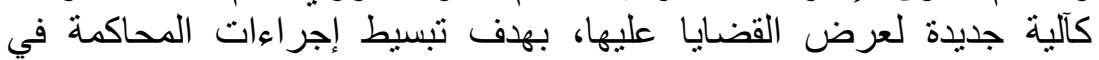

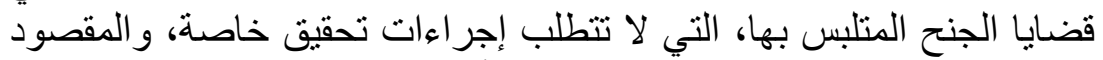
من وراء ذللك هو تللك الجنح التي تكون أدلة الاتهام واضحة فيهاء لتها، وتكون

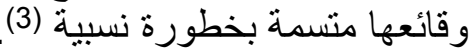

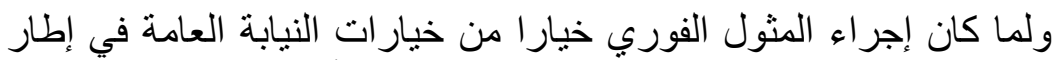

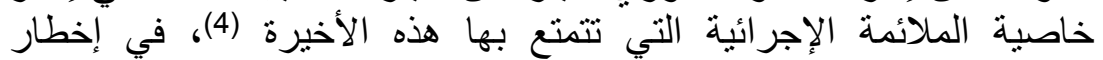

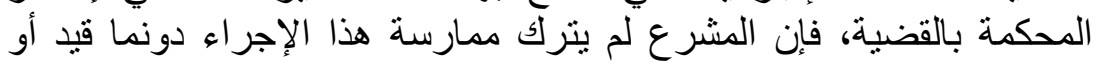

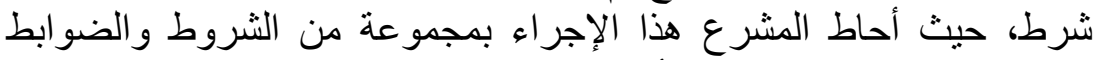

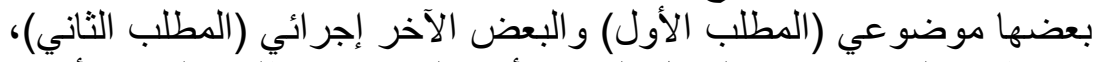

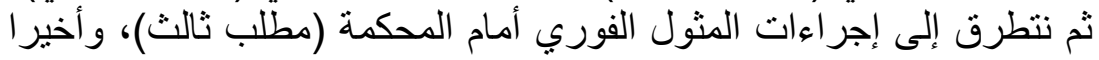
نتطرق إلى تقييم نظام المثول الفوري (مطلب رابع). 
المطلب الأول: الثروط الموضوعية للمثول الفوري:

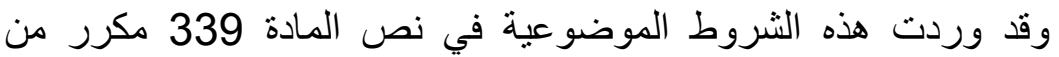

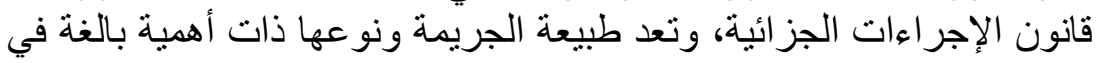

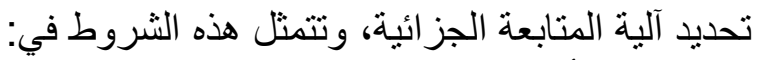

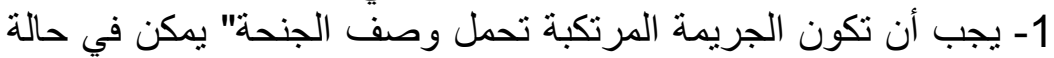

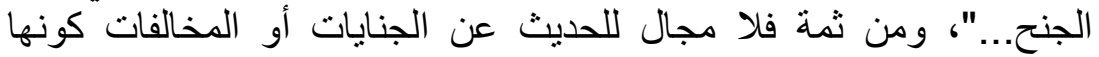

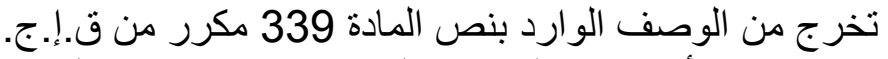

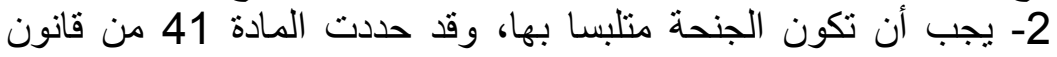
الإجراءات الجزائية حالات التلبس، حالتان منها تعد تلبسا حقيقان التيا، فيما تعد الحالة الثالثة تلبسا حكميا، و هذه الحالات التات هي:

* إذا كانت الجريمة مرتكبة في الحال التها أو عقب التب ارتكابها.

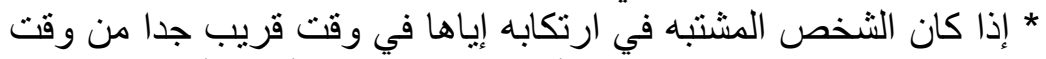

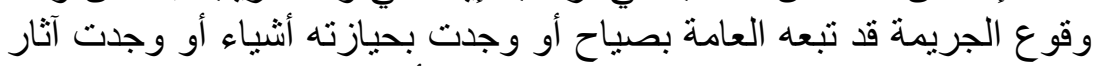

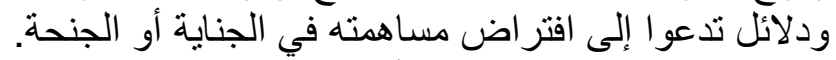

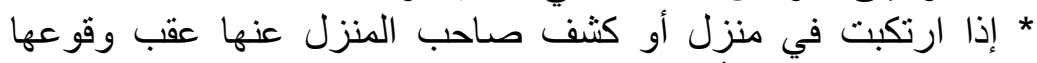
وبادر في الحال باستدعاء أحد ضباط الثبا الثرطة القضائية لإثباتها.

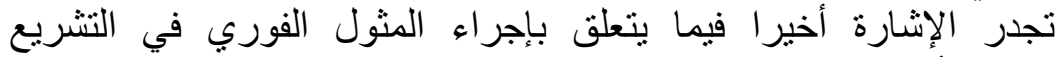

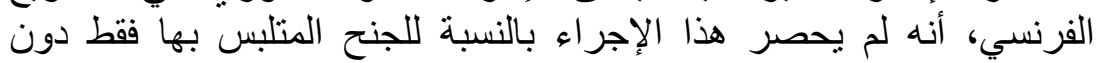

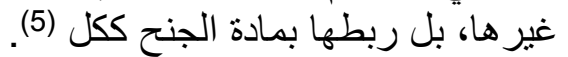

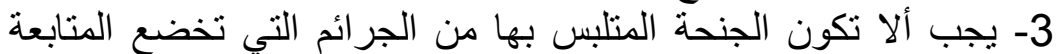

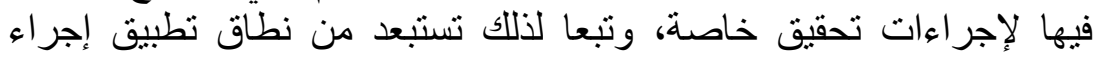

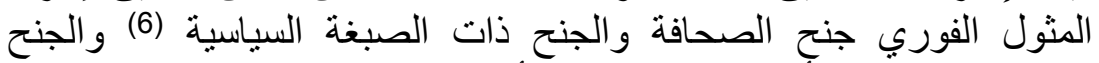

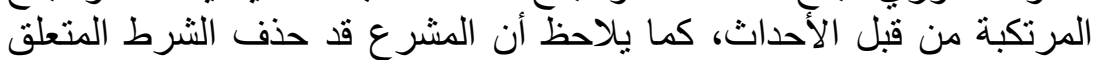

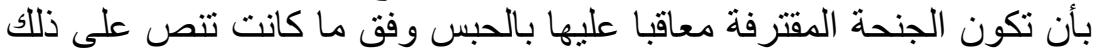

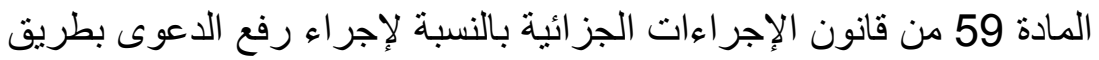
إجر اء التلبس.

المطلب الثاني: الثروط الإجرائية:

إلى جانب الثروط الموضوعية التي سبق وأن رأيناها، فإنه يتطلب الأمر

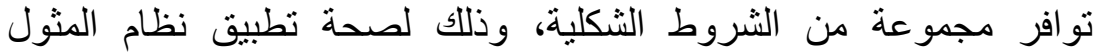

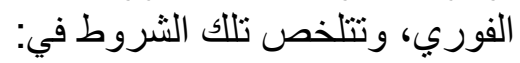

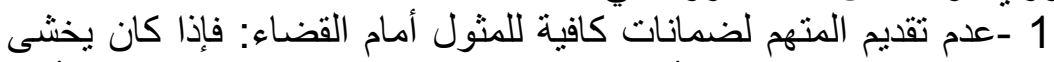

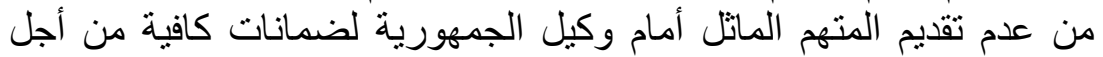

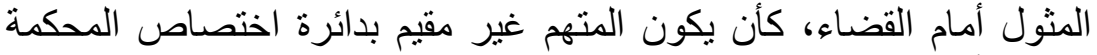

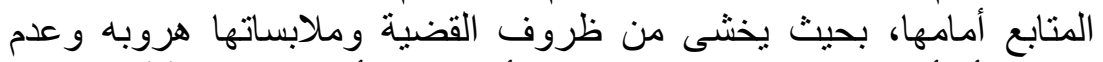

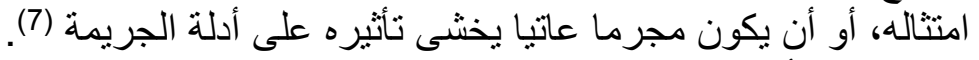

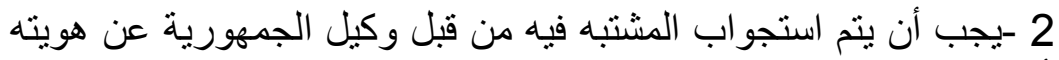

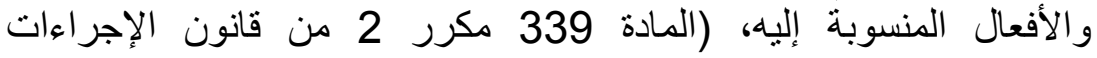
الجز ائية).

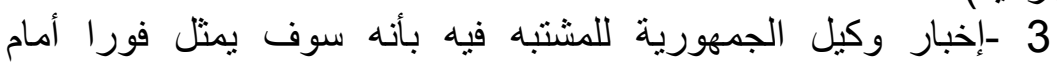

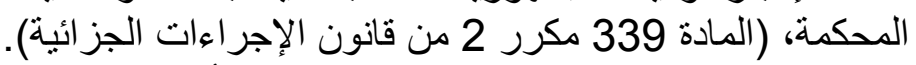

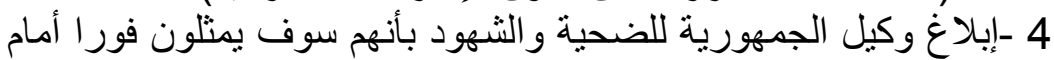
المحكمة، (المادة 339 مكرر 2 من قانون الإجر اءعات الجز ائية). 
5 -تمكين المشتبه فيه بالاستعانة بمحامي عند مثوله أمام وكيل الجمهورية،

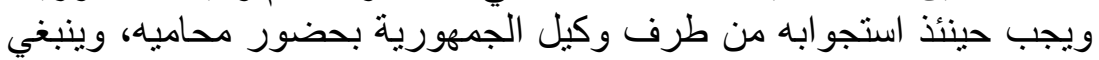
التنويه بذلك في محضر الاستجواب، (المادة 339 مكرر 3 من قانون الإجر اءات الجزائية).

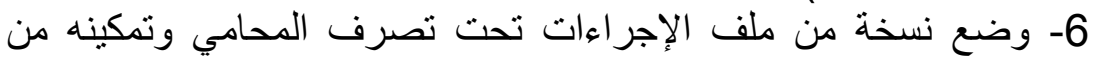

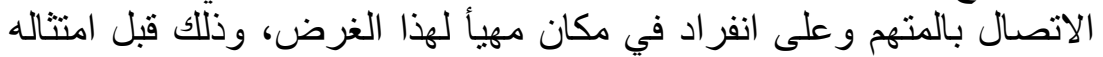

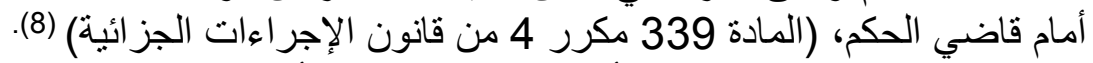

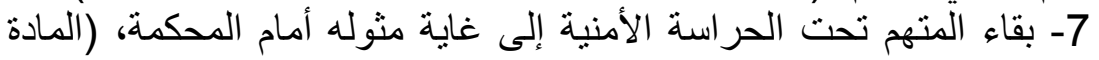
339 مكرر 4 من قانون الإجر اءات الجزائنة الأئة).

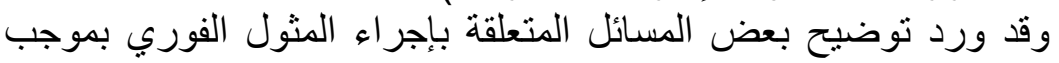

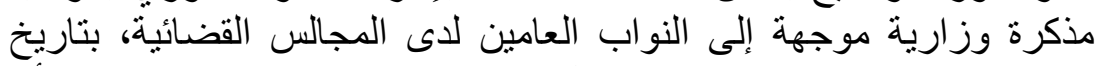

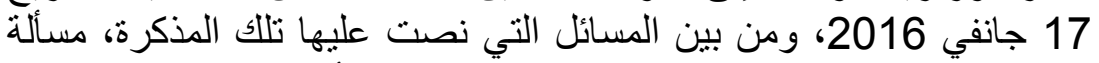

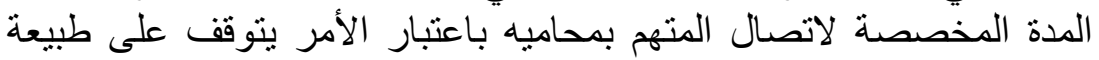

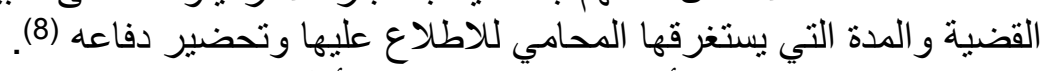

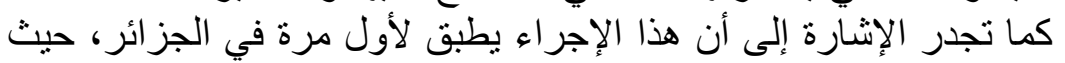

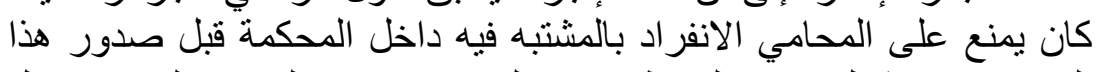

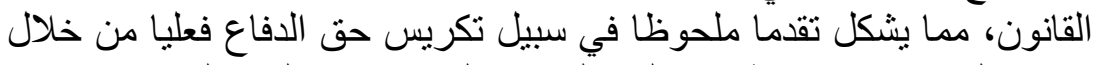

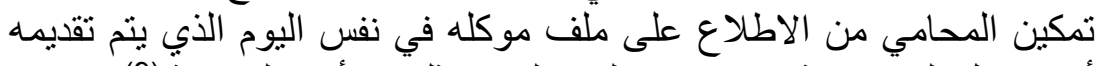

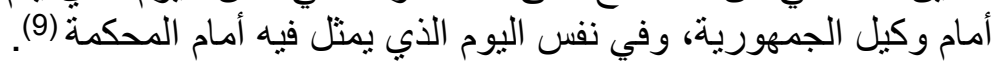
المطلب الثالث: إجراءات المثول القوري أمام المحكمة:

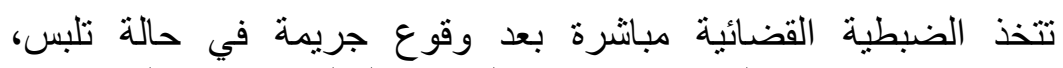

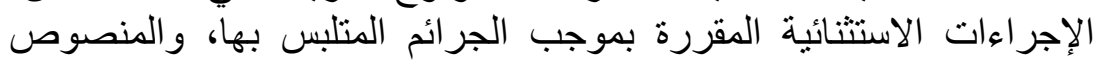

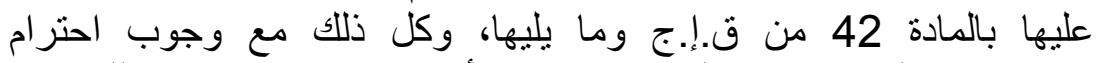

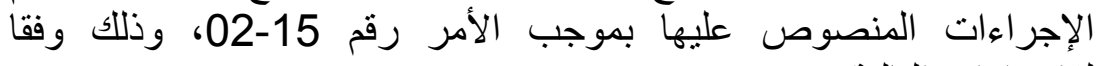

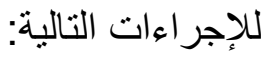

\section{1 -إجراعات تقديم المشتبه فيه أمام وكيل الجمهورية:}

غالبا ما يتم وضع المشتبه فيه الذي تم القبض عليه من قبل أفراد الضبطية

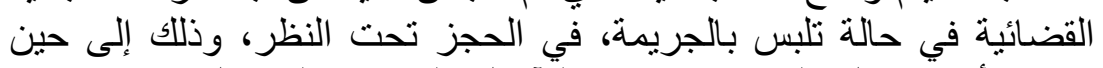

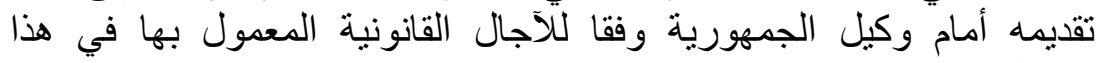
المجال.

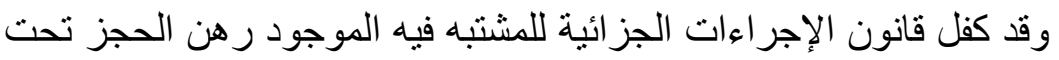

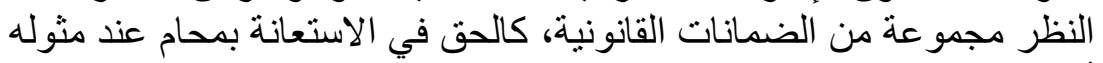

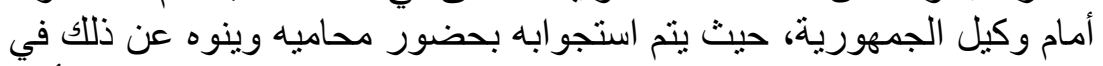

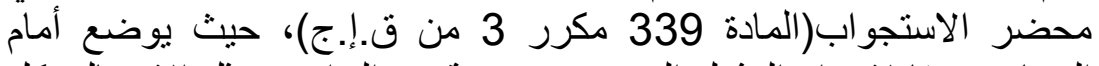

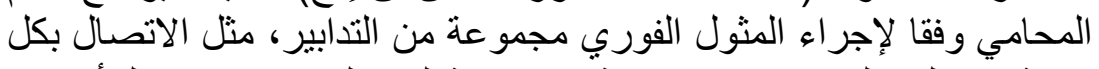

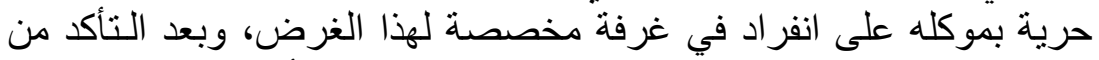

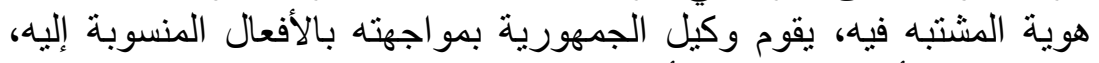

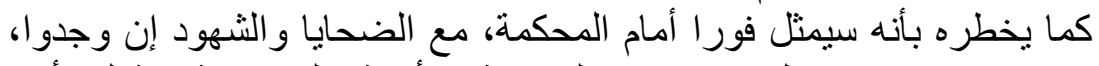

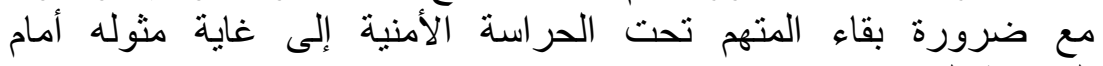
المحكمة(المادة 339 مكرر 3و 4 من ق.إ.ج.ج.). 


\section{2- 2 إجراءات مثول المتهم أمام المحكمة:}

تعقد جلسة المثول الفوري أمام قسم الجنح، حيث يرأسها إما رئيس

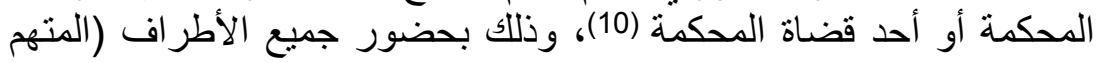

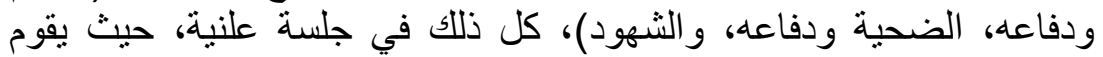

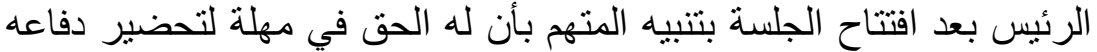

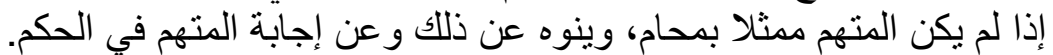

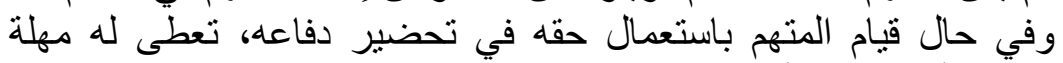

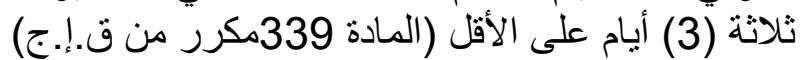

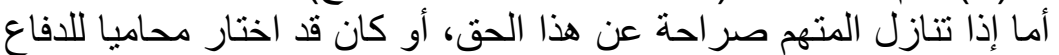

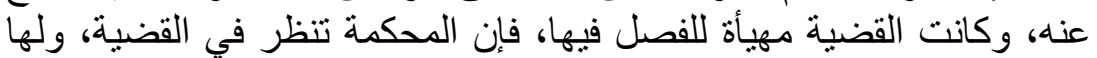

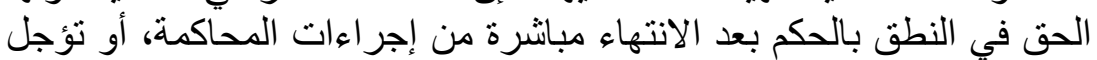
القضية إلى أقرب جلسة من أجل النطق بالحكم (11).

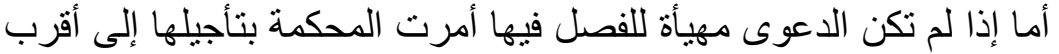

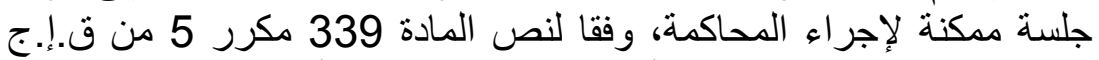

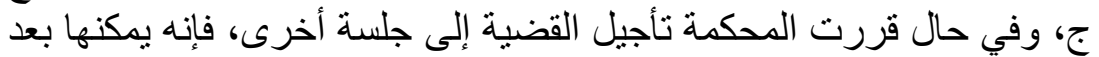
الاستماع إلى طلبات النيابة ودفاع المتهم:

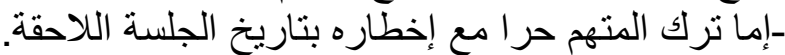

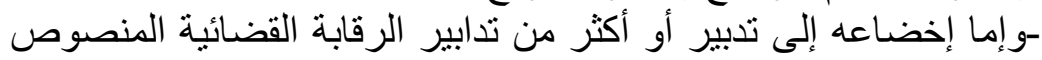

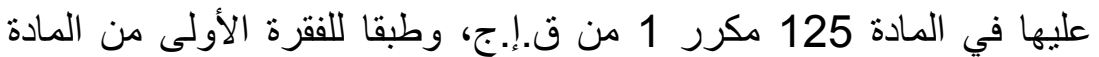
339 مكرر 7 من ق.إ.ج، تتولى النيابة العامة تنفيذ التدابير القضائية المقررة الإني من طرف المحكمة.

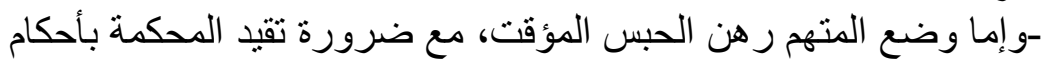
المادة 1/358 من ق.إ.ج، حيث يدخل ذلإنك كله في نطاق السلطة التقديرية

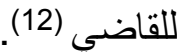
وتجدر الإشارة أخيرا إلى أن الأوامر التي تصدر ها المحكمة في الحالات

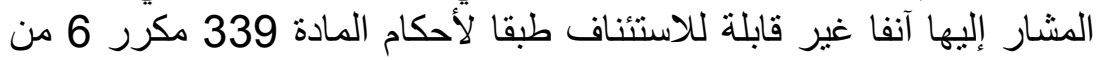
ق.إ.ب. المطلب الرابع: تقييم نظام المثٔول الفوري:

رغم المزايا الكثيرة التي يحققها نظام المثول الفوري، لاسيما من حيث إنباء

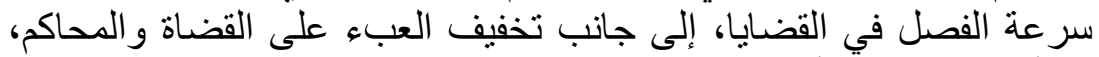

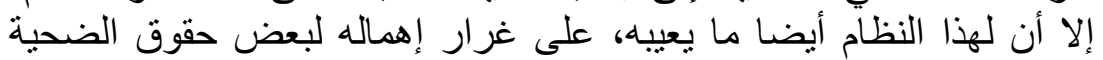

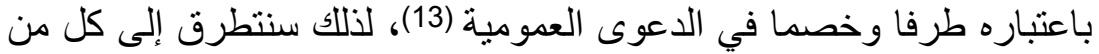

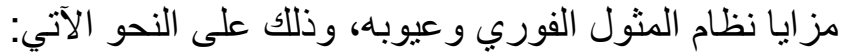

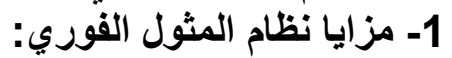

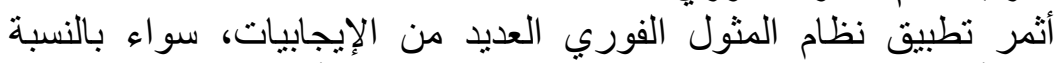

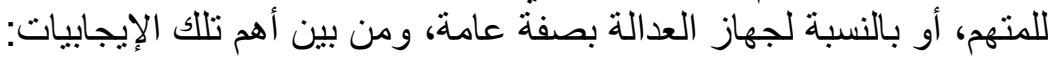
- تقرير ضمانات كبيرة للمتهح من خلال التقليل من مدة الحجز تحت التحت

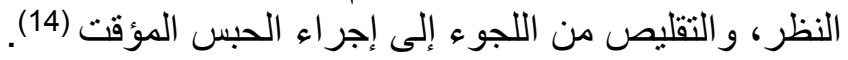

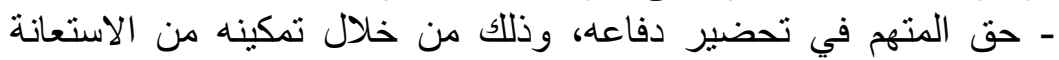

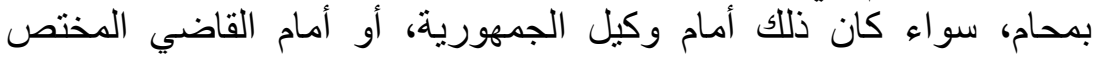
بالفصل في الدعوى (15). 
-بساطة وسهولة وسرعة الفصل في القضايا التي تحال بطريق المثول

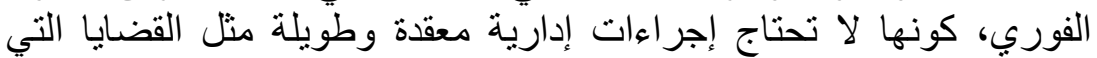

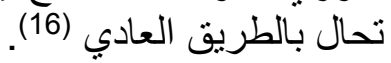
ـانتقال صلاحيات وكيل الجمهورية بالإيداع في حالة التهاري التلبس، إلى قاضي

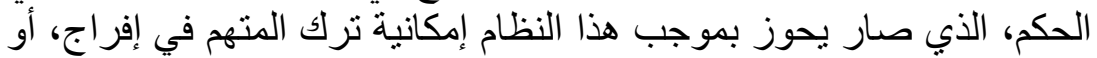

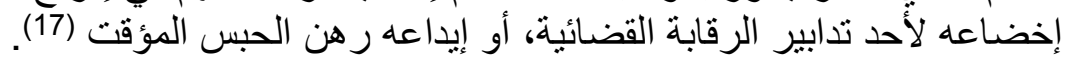

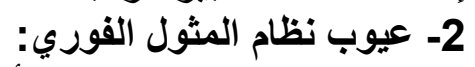

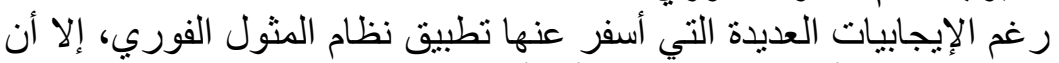

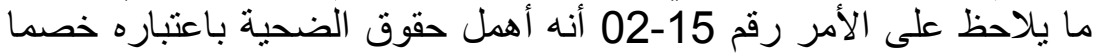

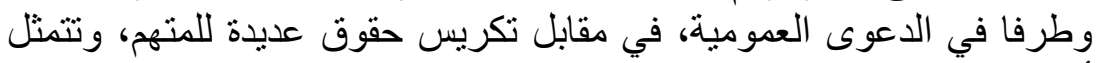

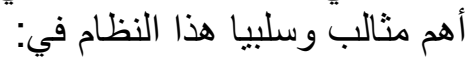

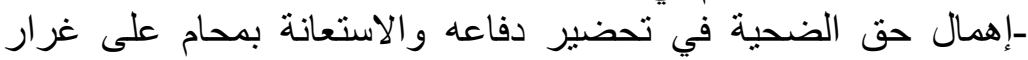
المتهم (18). - (18).

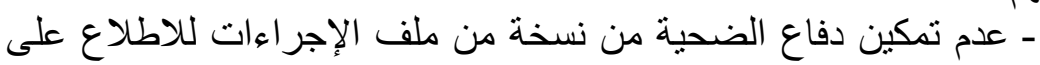
الملف (19). ـعدم النص على قيام رئيس قسم الجنح على تتبيه الضحية بحقه في تحضير دفاعه بخلاف الأمر بالنسبة للمتهم (20).

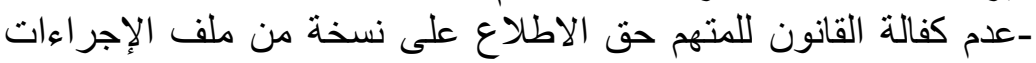

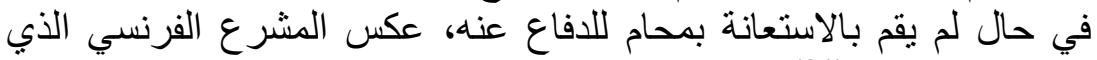
تفطن لهذه النقطة (21).

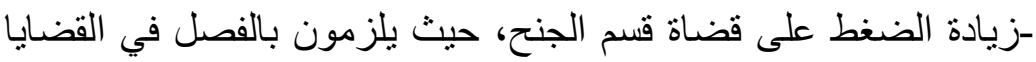

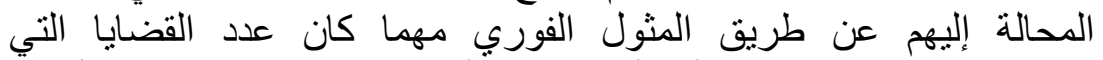

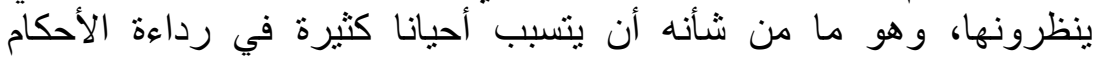
المنطوقة (22).

\section{المبحث الثاني: نظام الأمر الجزائي:}

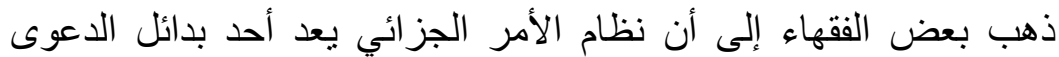

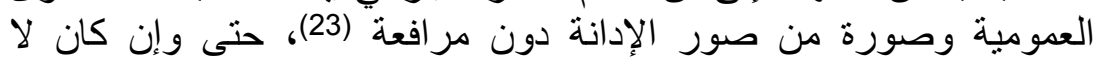

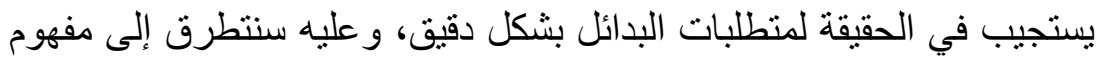

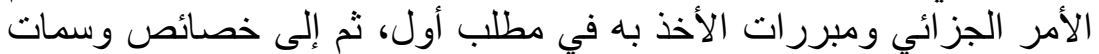

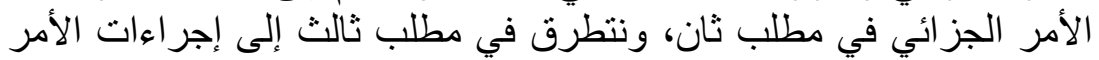

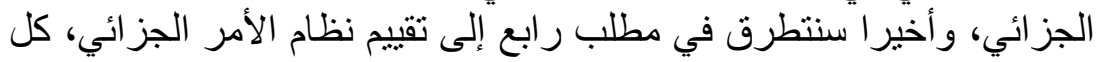

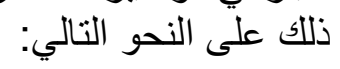
المطلب الأول: مفهوم الأمر الجزائي وشروط العمل به:

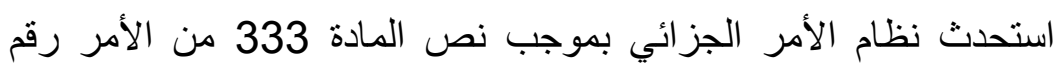
02-15 المعدل والمتمم لقانون الإجراءات الجزائية، وذللك كطريق يسلكه الأئ

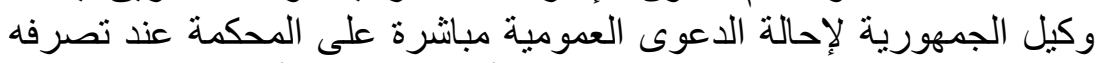

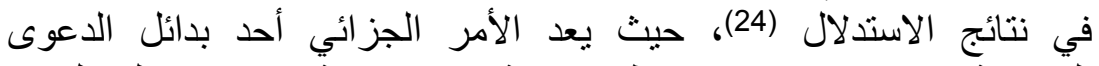

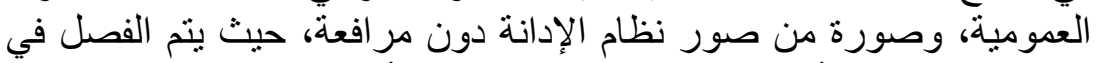
القضايا البسيطة أمام جهة قضائية بموجب ألماء أمر قضائي، دونة دونما اتباع لإجر اءات المحاكمة العادية. 
ويعرف الأمر الجزائي بأنه:" أمر قضائي بتوقيع العقوبة المقررة دون

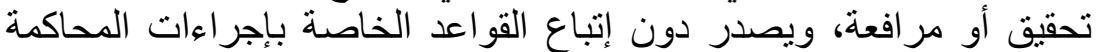

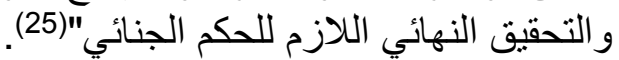

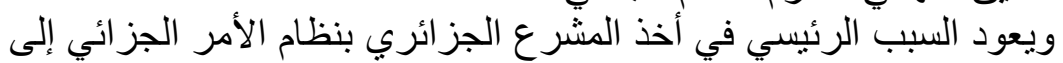

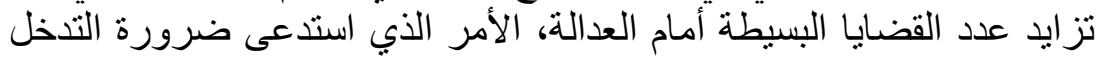

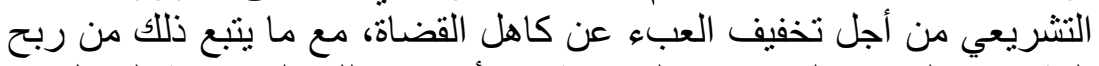

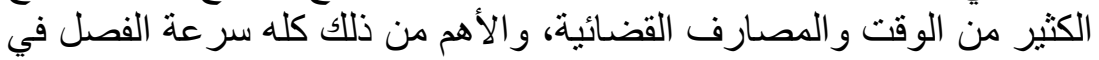

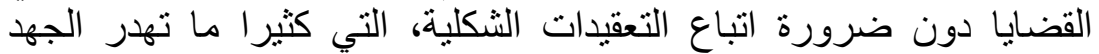

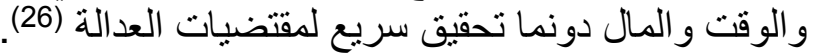

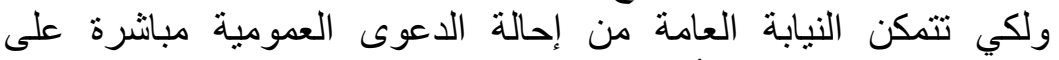

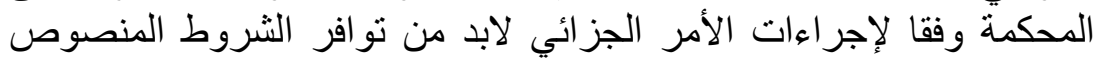

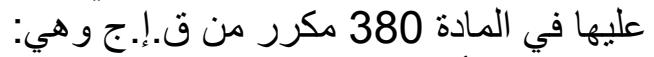

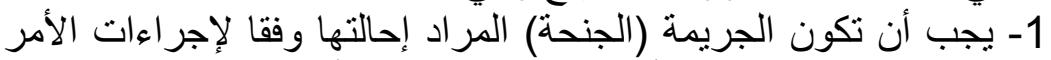

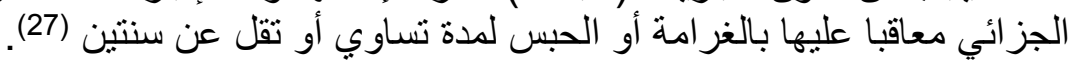

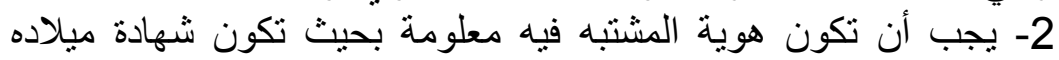
مرفقة بملف الإجر اءات (28) 3- يجب أن تكون الوجرائ الوائع المنسوبة للمتهم ثابتة على أساس معاينتها

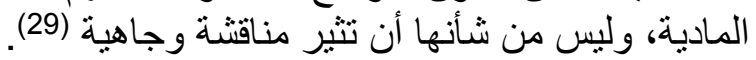

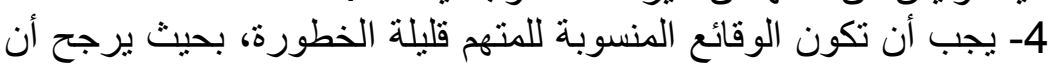

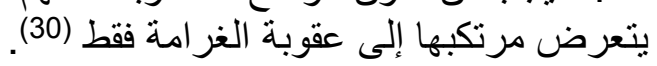

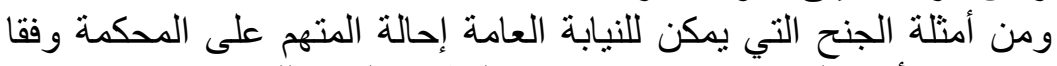

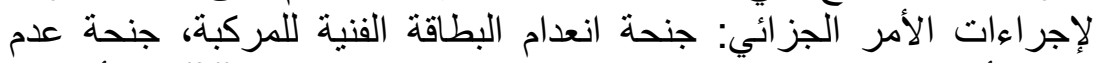

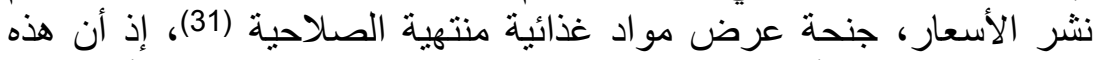

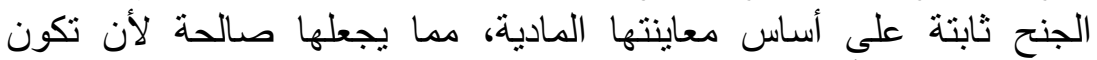
موضوع دعوى أمر جزائي.

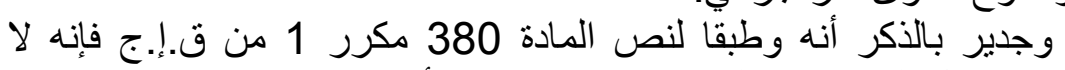

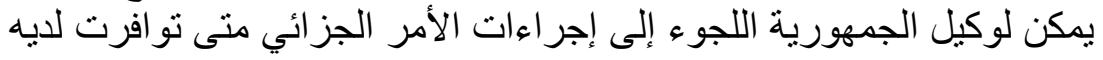

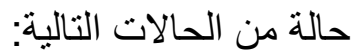
-إذا كان المتهم حدثا، لكون التحقيق وجوبيا في جر الأم الأحداث طبقا للمادة

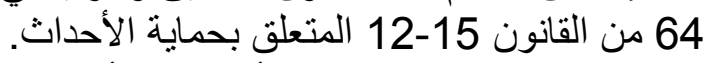

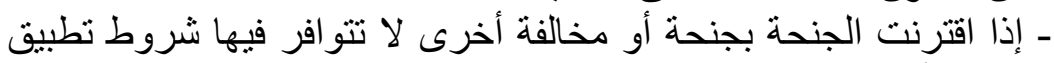
إجراءات الأمر الجزائي.

- إذا كان ثمة حقوق مدنية تستوجب مناقثنة وجاهية للفصل فيها (32).

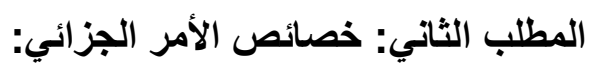

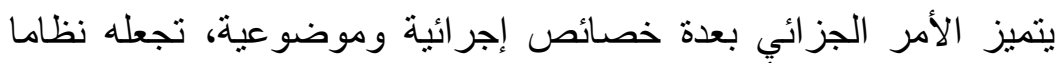

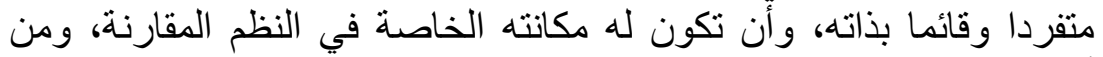
أبرز تلأك السمات:

\section{1- اقتصار تطبيقه على الجرائم البسيطة:}

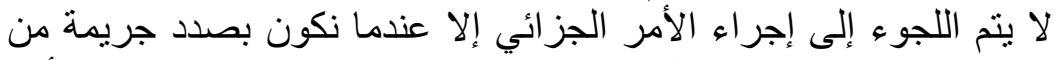

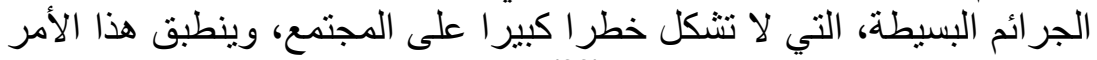

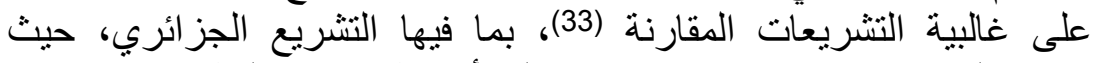

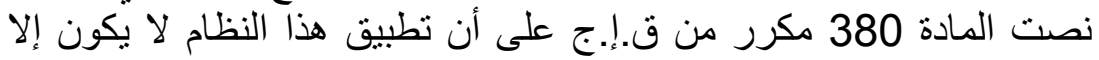
في الجرائم البسيطة فقط، وهذا النوع من الجرائم يكون عادة من الجرائم 
المادية، أي تللك الوقائع التي تكون ثابتة على أساس معاينتها المادية، وليس

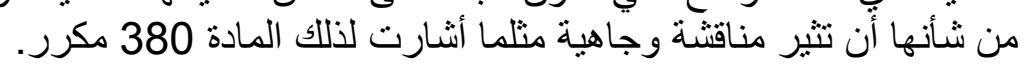

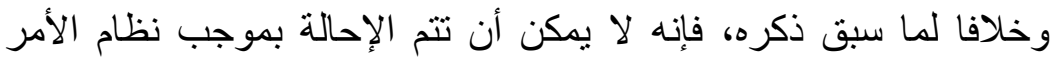

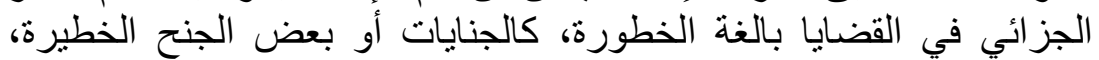

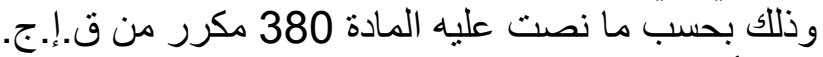

$$
\text { 2- الأمر الجزائي إجراء جوازي: }
$$

يعد اللجوء إلى إجراءي إجراء الأمر الجزئ الجزائي أمرا جوازيا، بحيث تملك النيابة

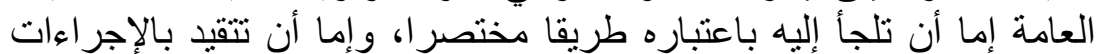

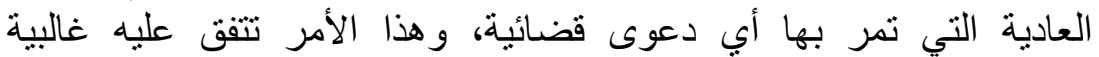

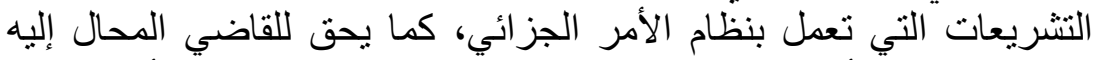

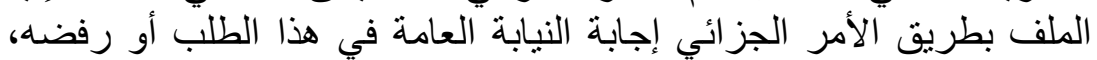

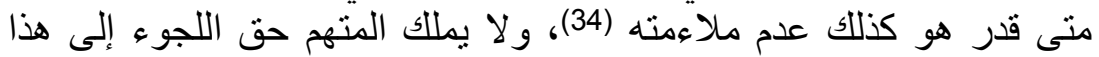

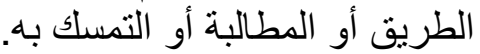

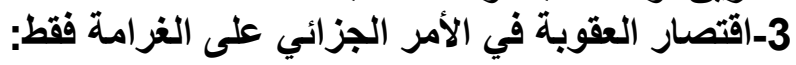

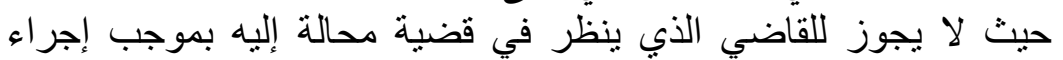

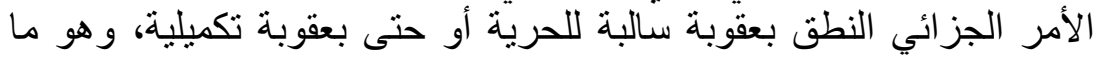

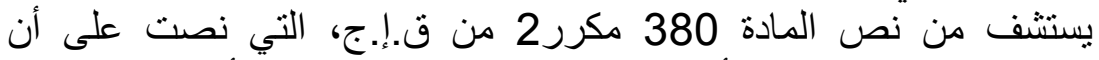

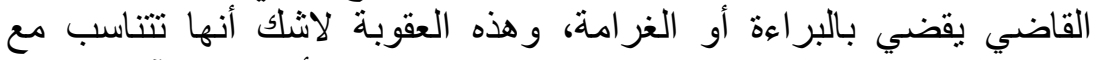

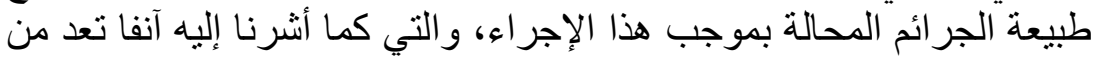

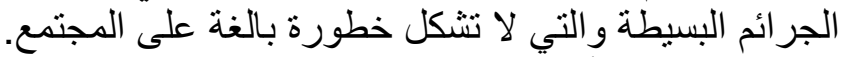

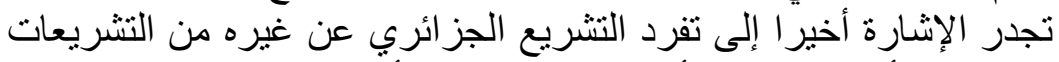

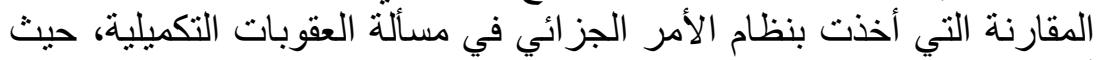

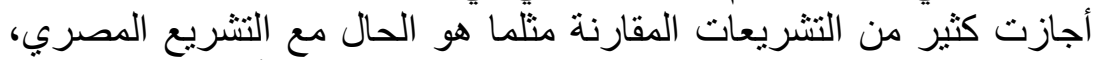

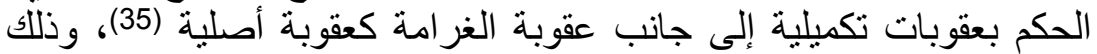

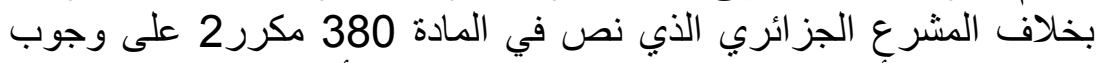

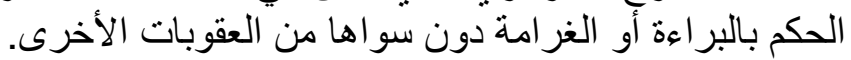

4- عدم جواز إتباع الإجراء العادية للمحاكمة عند مباثرة الثرة هذا الإجراء:

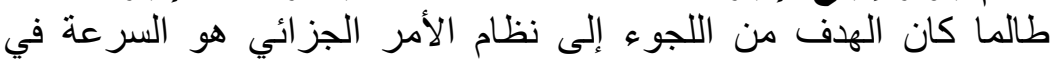

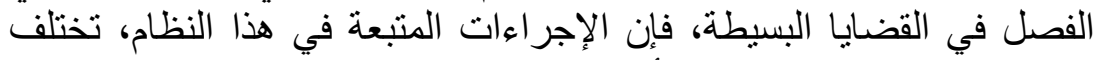

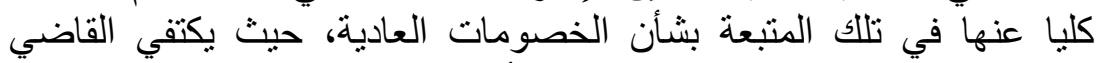

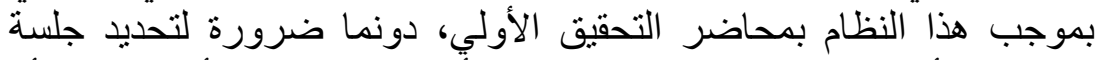

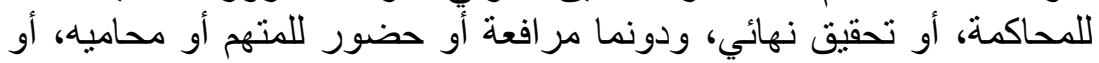

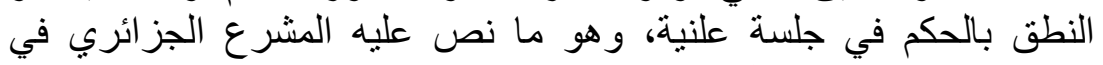

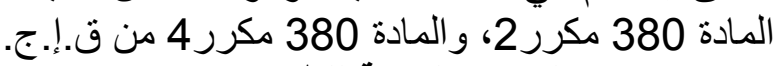
5- عدم اتباع القواعد العادية للطعن:

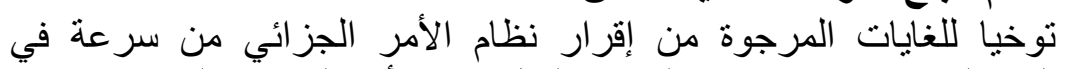

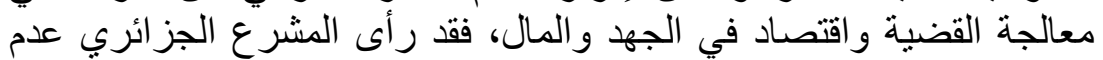

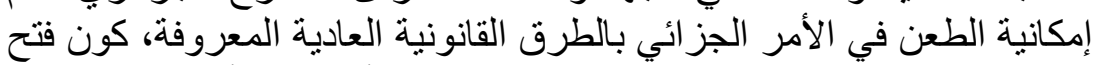

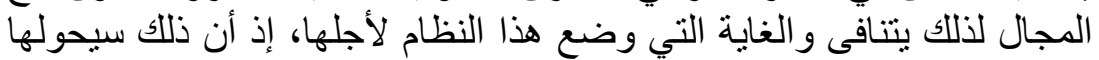

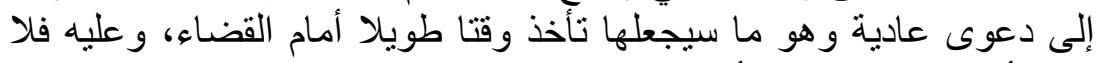

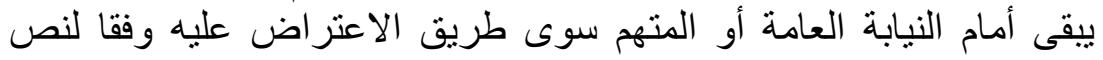

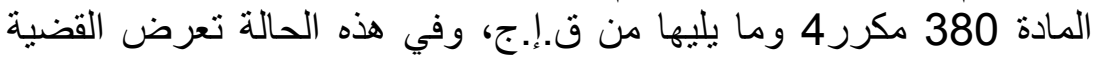

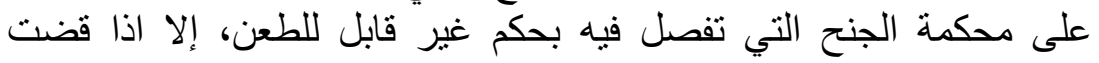




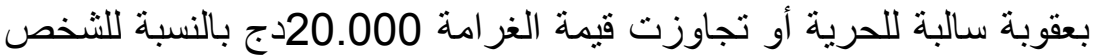

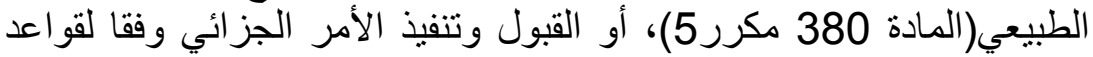
تنفيذ الأحكام الجزائية (38).

$$
\text { المطلب الثالث: إجراءات الأمر الجهاء الجزائي: }
$$

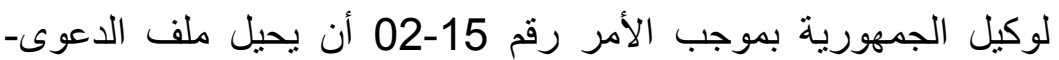
بطريق الأمر الجزائي- إلى محكمة الجنح مرفقة بمحاضر الضبطية القضائية ومشفوعا بطلباته، وذللك للفصل فيها، ورغم عدم الإن تحديد كيفيات الإحالة الإنة

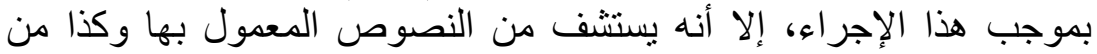

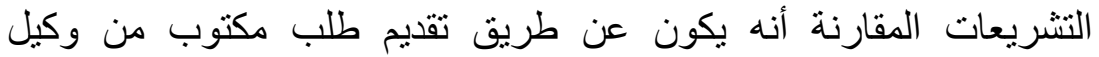
الجمهورية إلى قاضي الجنح المختص بنظر الدئه الدوى، يلتمس منه فيه إصدار أمر جز ائي لعقوبة معينة (37) الجنية

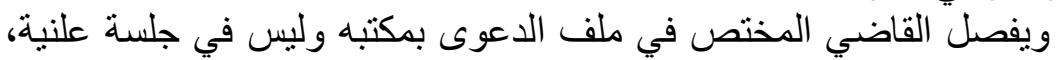

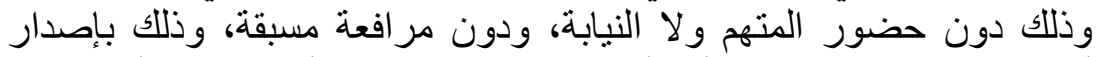

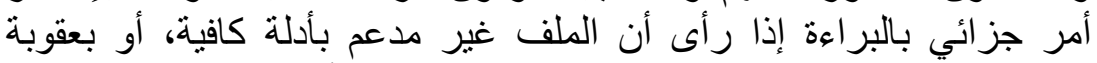

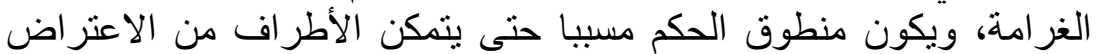
عليه (38)

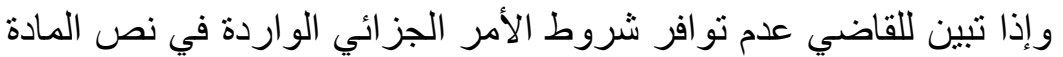

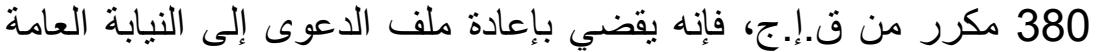

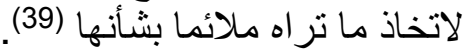

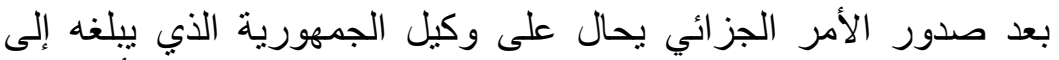

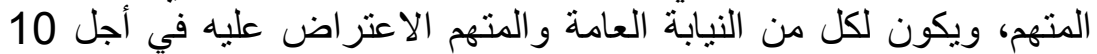

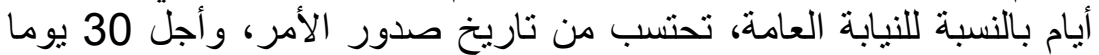

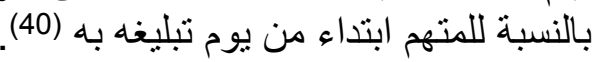

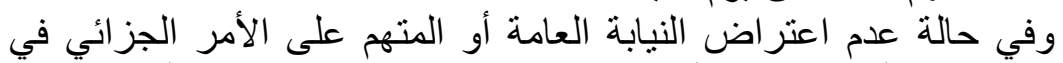

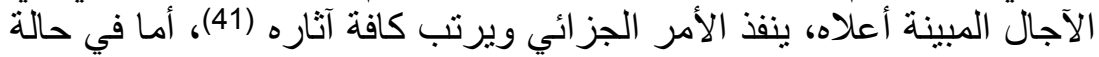

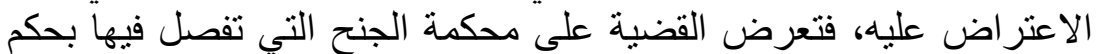

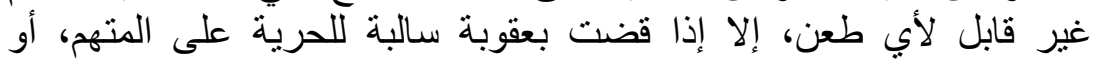

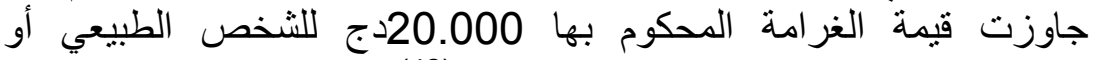

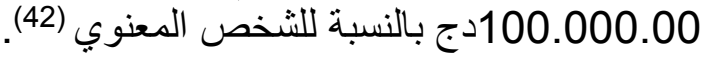

$$
\text { المطلب الرابع: تقييم نظام الأمر الجزائي: }
$$

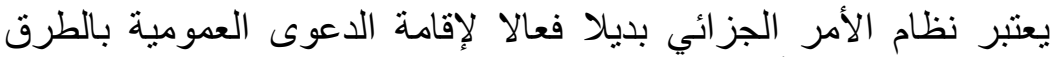

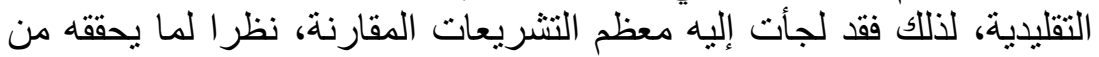

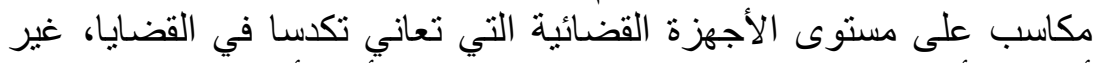

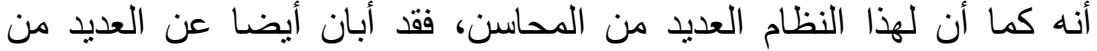

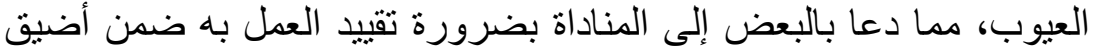

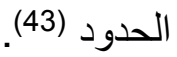
1- 1 - مزايا نظام الأمر الجزائي:

من خلال استعر اض نظام الأمر الأمر الجزائي يتبين لنا الأهمية التي يكتسيها هذا الإجر اء وذللك من خلال: - تبسيط الإجر اءات الجزائية أمام المتقاضين.

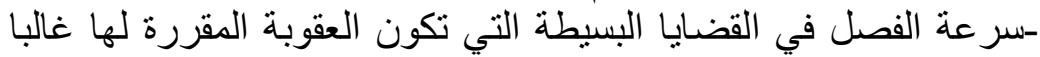
هي الغرامة أو الحبس لمدة تقل عن السنتين. 
-أن العقوبة التي تصدر بطريق الأمر الجزائي تكون بالغرامة فقط كعقوبة

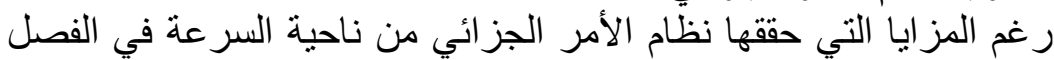

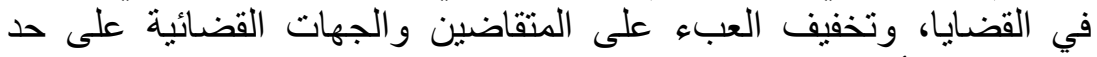

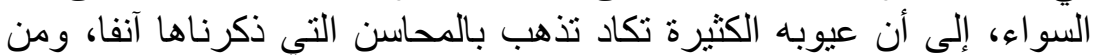

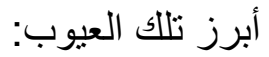

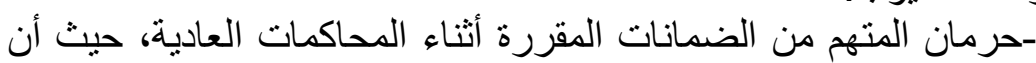

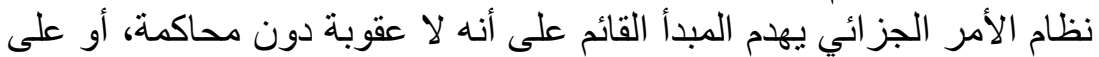

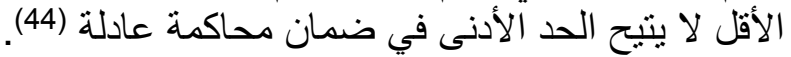

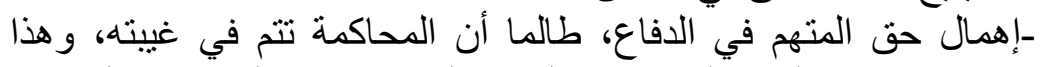

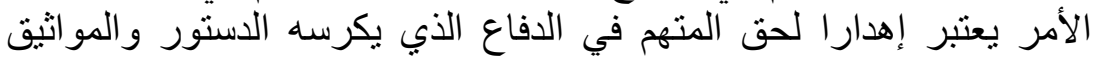
الدولية المختلفة (45).

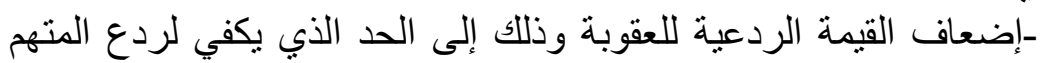

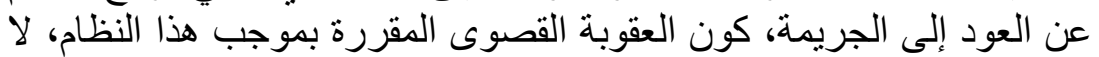

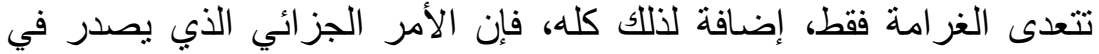
مواجهة المتهم لا يدون في صحيفة السوابق القضائية للمتهم (46).

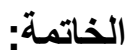

يمكن القول من خلال استعر اض نظامي المثول الفوري والأمر الجزائي

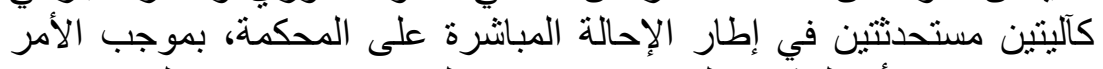
رقم 15-02، أن المشرع الجزائري قد وفق إلى حد كبير من خلال استحداث

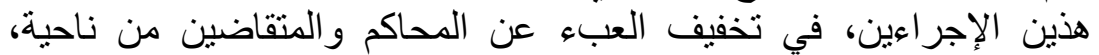

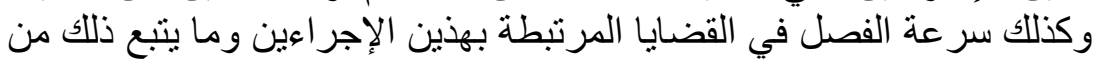
اقتصاد للجهد و النفقات. ومن خلال دراستتا المختصرة هذاته، فقد توصلنا إلى جملة من النتائج والتوصيات التي نوردها كما يلي:

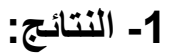

ـ الجهة القضائية المختصة بنظر الجنح التي تحال عن طريق نظام الإحالة

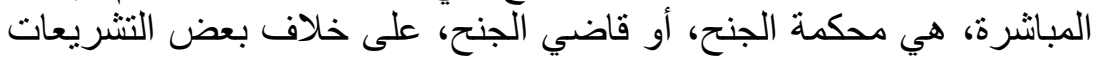

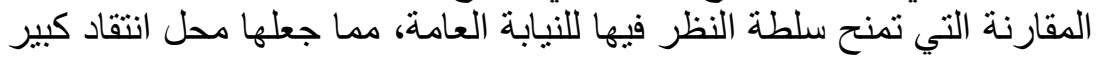

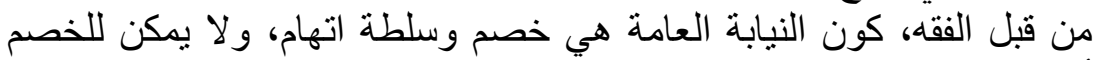

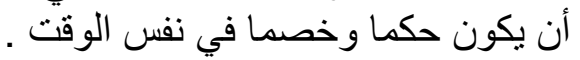

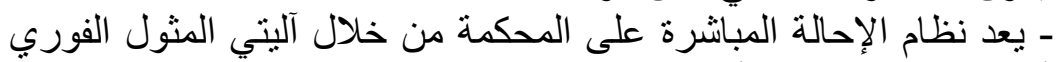

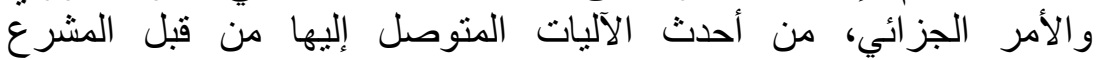
الجزائري، و التي عززتي، من سر عة الفصل في القضايا التي تحال من خلال

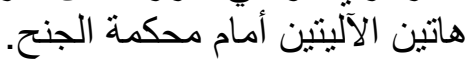

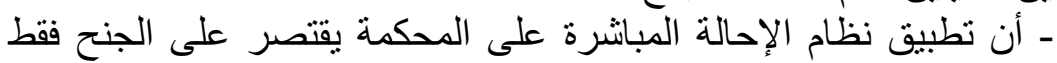

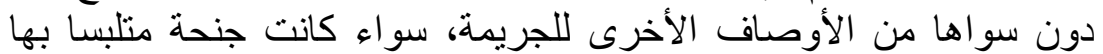

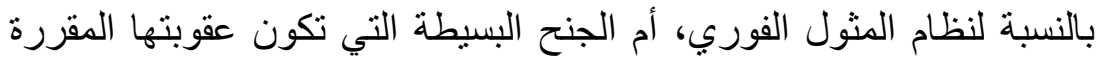

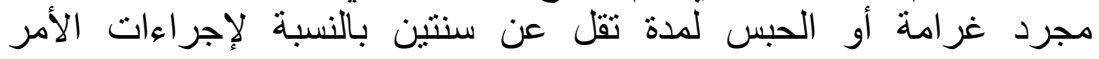

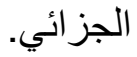


- أن نظام الإحالة المباشرة على المحكمة يهمل دور الضحية نماما في

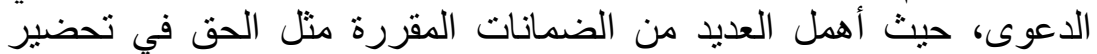

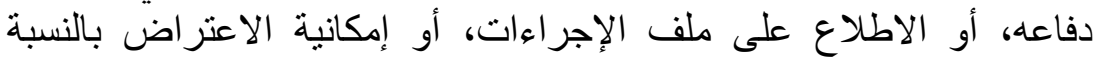

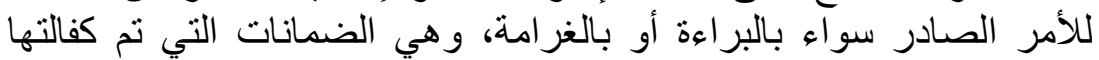
للمتهم دون الضحية.

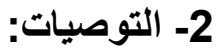

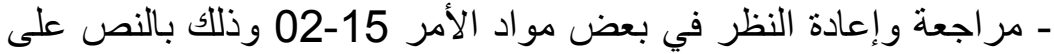

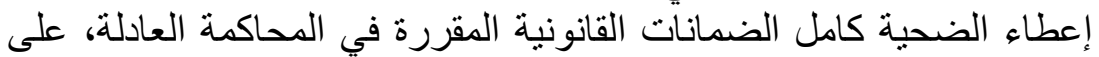

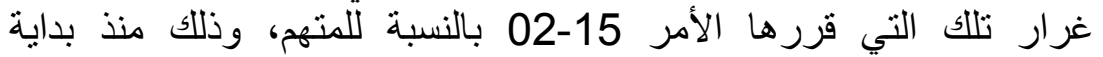
إجر اءات الإحالة المباشرة إلى غائل الإية نهايتها.

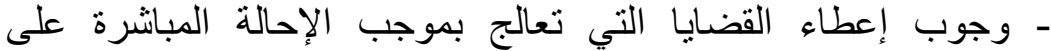

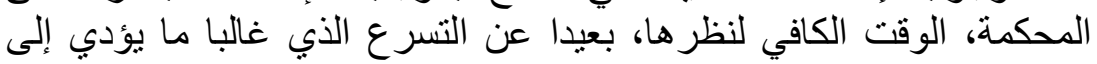
عكس النتائج المرجة من تطبيق هذا النظام.

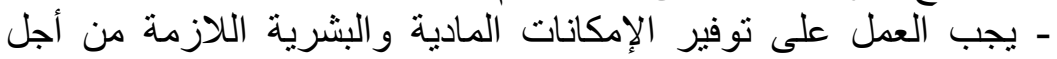

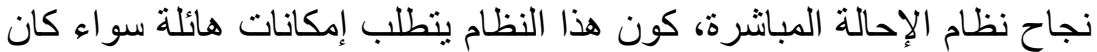

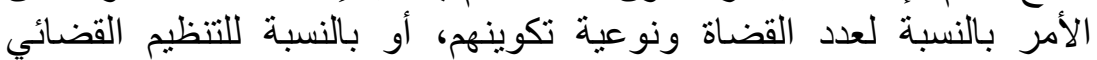

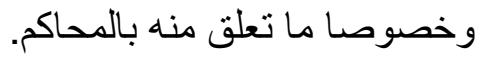

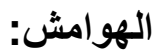

1- الأمر رقم 15-15-02 المؤرخ في 23 يوليو 2015 المعدل و المتمم للأمر رقم 156-156 المؤرخ في 8 يونيو 1966 المتضنمن قانون الإجراءات

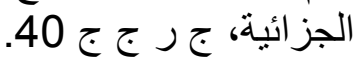

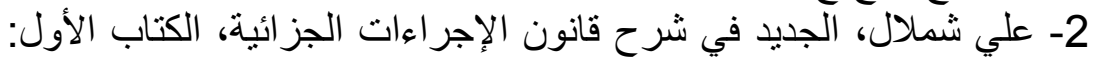

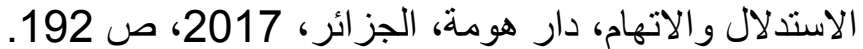

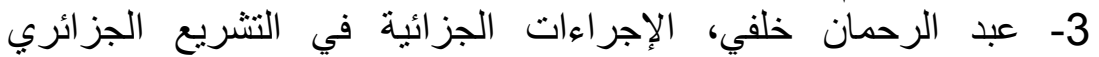

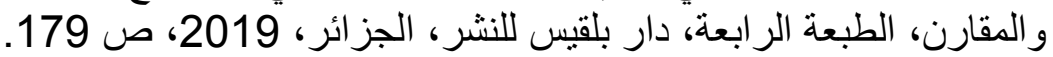

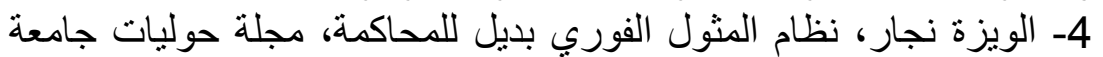
قالمة للعلوم الاجتماعية والإنسانية الجزائر : جامعة 8 مائ لإي 1945 قالمة،

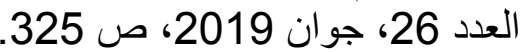

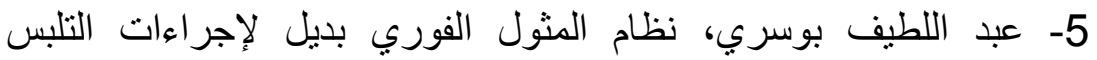
الجزائر: جامعة عبد الرحمان ميرة، العدد 1، المجلد 15، 2017، لإيل صل

6- أحمد بولمكاحل، المثول الفوري كبديل للمحاكمة في الجرائم البسيطة،

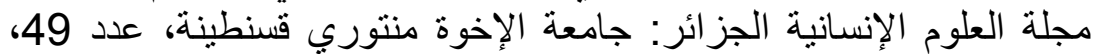
المجلد ب، جوان 2018، صلان صل 23. 7- أحمد بولمكاحل، المرجع نفسه، صل صل 2318 23.

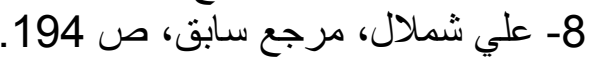

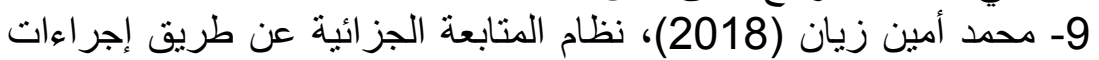

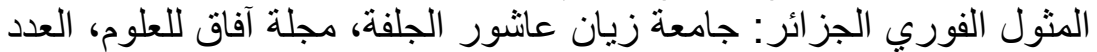

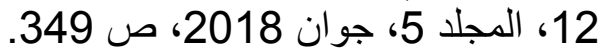

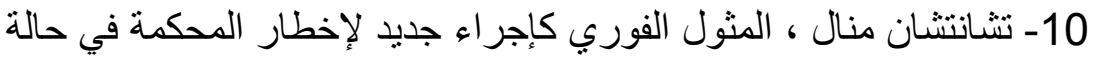

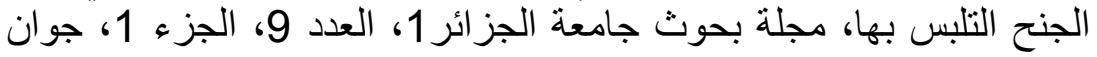




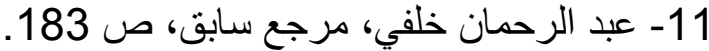

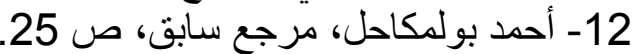

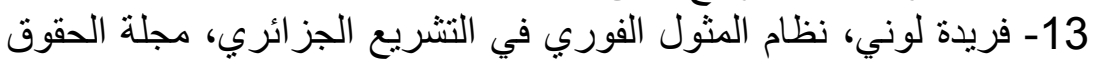

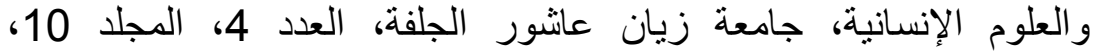

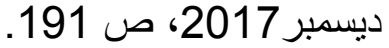
14- عبد الله دريسي، السعيد بولواطة، إجراءاءت المثنول الفوري في القانون

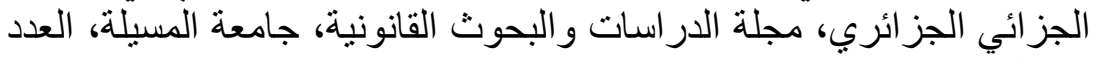

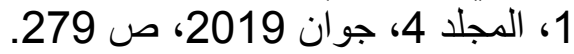

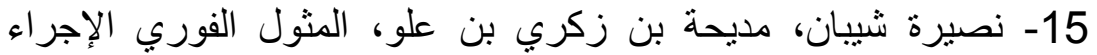

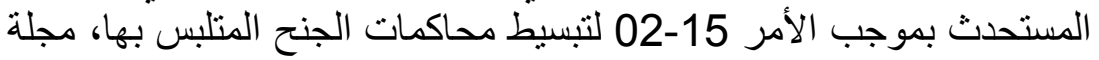

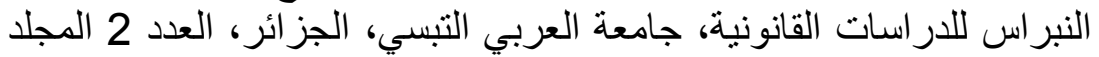

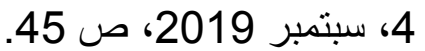

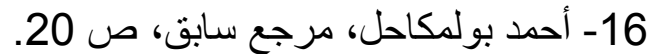

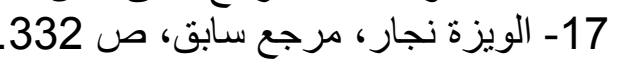

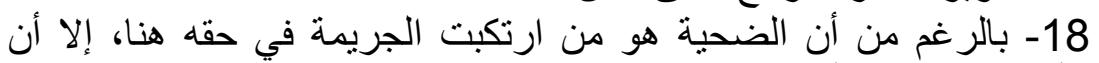

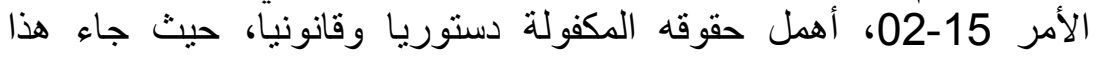
القانون لحماية المتهم على حساب الضحية، أنظر : عبد الرحمان خلفي، مرجع حلئ لهاء

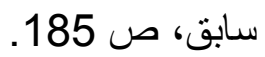

19- محمد أمين زيان، مرجع سابق، ص 254.

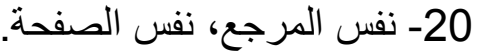

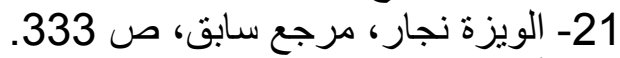

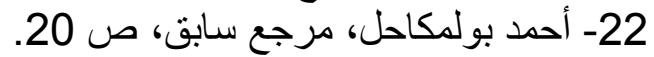

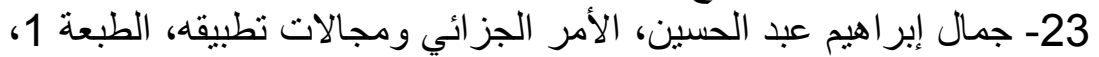

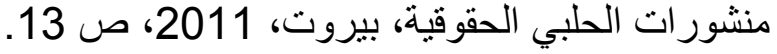

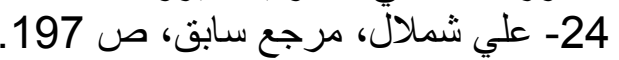

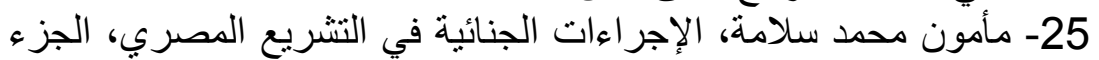

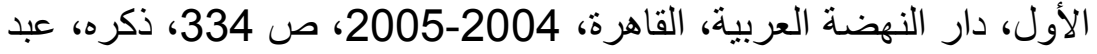

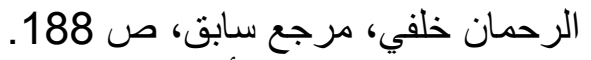

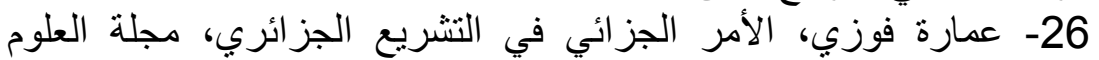

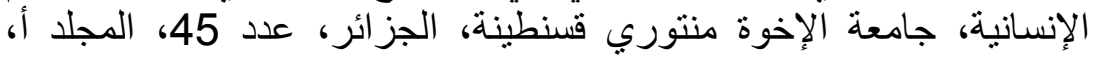

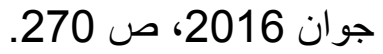
27- 28 علي شملال، مرجع سابق، ص صل 2016 197.

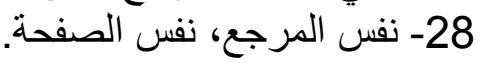

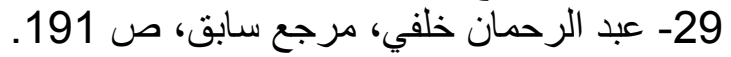

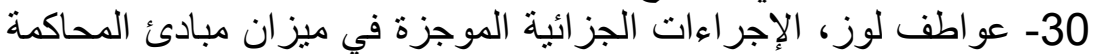

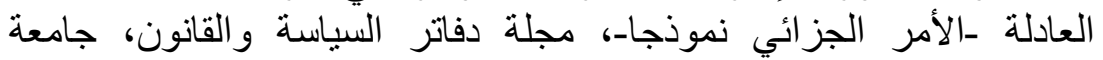

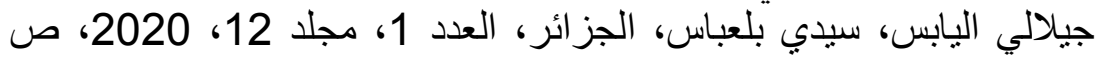

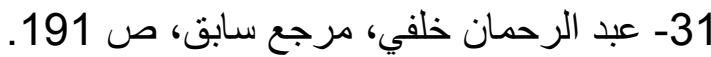

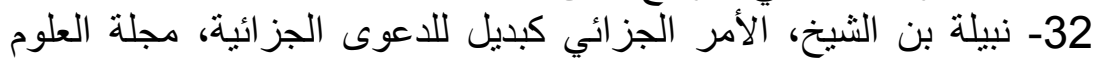

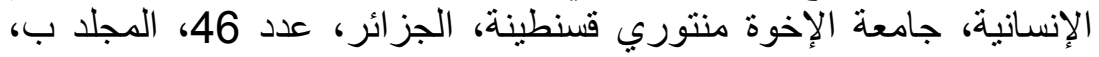

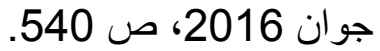
33- فوزي عمارة، مرجع سابق، ص 2016 ص 271. 


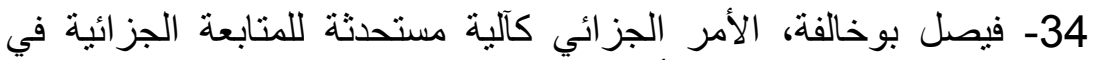

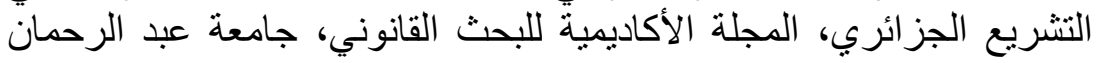

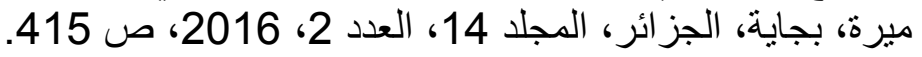

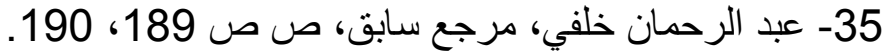

36- فوزي عمارة، مرجع سابق،

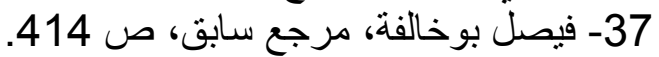

38- راضية مشري، الأمر الجزائي كآلية للمتابعة الجزائية في التئية التشريع

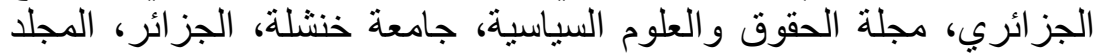

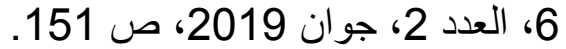

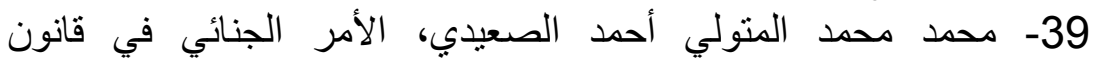

الإجراءات الجنائية، الطبعة 1، دار الفكر و ألقانون، القاهرة، 2011، صد

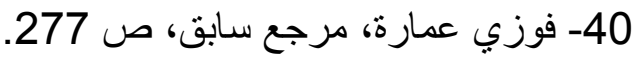

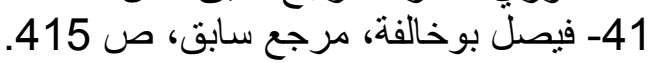

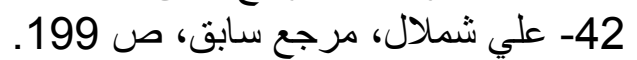

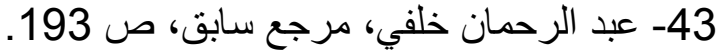

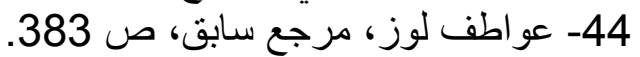

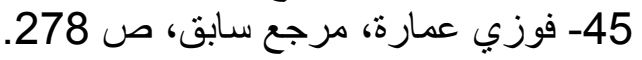

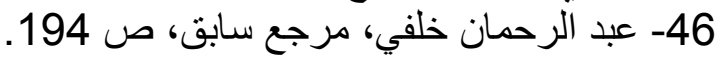

